\title{
Histone Deacetylase Inhibitors: An Attractive Therapeutic Strategy Against Breast Cancer
}

\author{
CHRISTOS DAMASKOS ${ }^{1,2^{*}}$, SERENA VALSAMI ${ }^{3 *}$, MICHAEL KONTOS ${ }^{4 *}$, ELEFTHERIOS SPARTALIS ${ }^{2}$, \\ THEODOROS KALAMPOKAS ${ }^{5}$, EMMANOUIL KALAMPOKAS ${ }^{6}$, ANTONIOS ATHANASIOU ${ }^{4}$, DEMETRIOS \\ MORIS $^{7}$, AFRODITE DASKALOPOULOU ${ }^{2,8}$, SPYRIDON DAVAKIS ${ }^{4}$, GERASIMOS TSOUROUFLIS ${ }^{1}$, \\ KONSTANTINOS KONTZOGLOU ${ }^{1}$, DESPINA PERREA ${ }^{2}$, NIKOLAOS NIKITEAS ${ }^{2}$ and DIMITRIOS DIMITROULIS ${ }^{1}$ \\ ${ }^{1}$ Second Department of Propedeutic Surgery, ${ }^{4}$ First Department of Surgery, Laiko General Hospital, \\ Medical School, National and Kapodistrian University of Athens, Athens, Greece; \\ ${ }^{2}$ N.S. Christeas Laboratory of Experimental Surgery and Surgical Research, Medical School, \\ National and Kapodistrian University of Athens, Athens, Greece; \\ ${ }^{3}$ Blood Transfusion Department, Aretaieion Hospital, Medical School, \\ National and Kapodistrian Athens University, Athens, Greece; \\ ${ }^{5}$ Assisted Conception Unit, Second Department of Obstetrics and Gynecology, Aretaieion Hospital, \\ Medical School, National and Kapodistrian University of Athens, Athens, Greece; \\ ${ }^{6}$ Gynaecological Oncology Department, University of Aberdeen, Aberdeen, U.K.; \\ ${ }^{7}$ Lerner Research Institute, Cleveland Clinic, Cleveland, OH, U.S.A; \\ ${ }^{8}$ School of Biology, National and Kapodistrian University of Athens, Athens, Greece
}

\begin{abstract}
With a lifetime risk estimated to be one in eight in industrialized countries, breast cancer is the most frequent type of cancer among women worldwide. Patients are often treated with anti-estrogens, but it is common that some tumors develop resistance to therapy. The causation and progression of cancer is controlled by epigenetic processes, so there is an ongoing interest in research into mechanisms, genes and signaling pathways associating carcinogenesis with epigenetic modulation of gene expression. Given the fact that histone deacetylases (HDACs) have a great impact on chromatin remodeling and epigenetics, their inhibitors have become a very interesting field of research. Aim: This review focused on the use of HDAC inhibitors as anticancer treatment and explains the mechanisms of therapeutic effects on breast cancer. We
\end{abstract}

This article is freely accessible online.

*These Authors contributed equally to this article.

Correspondence to: Christos Damaskos, MD, M. Sc., Ph.D., 17 Agiou Thoma Street, Athens, 11527, Greece. Mobile: +30 6948467790, Fax: +30 2132061772, e-mail: x_damaskos@yahoo.gr

Key Words: HDAC, histone, inhibitors, acetylation, epigenetics, breast, cancer, targeted, therapy, review. anticipate further clinical benefits of this new class of drugs, both as single agents and in combination therapy. Molecules such as suberoylanilide hydroxamic acid, trichostatin A, suberoylbis-hydroxamic acid, panobinostat, entinostat, valproic acid, sodium butyrate, SK7041, FTY720, N-(2-hydroxyphenyl)2-propylpentanamide, Scriptaid, YCW1, santacruzamate A and ferrocenyl have shown promising antitumor effects against breast cancer. HDAC inhibitors consists an attractive field for targeted therapy against breast cancer. Future therapeutic strategies will include combination of HDAC inhibitors and chemotherapy or other inhibitors, in order to target multiple oncogenic signaling pathways. More trials are needed.

Breast cancer is the most frequently diagnosed cancer and the second leading cause of cancer-related death among women worldwide. According to the American Cancer Society about $12 \%$ U.S. women will develop breast cancer during their lifetime. Moreover, in 2015, about 2,300 men were diagnosed with breast cancer and 440 died from the disease $(1,2)$.

In approximately $90 \%$ of breast cancer cases, estrogen receptor $\alpha(\mathrm{ER} \alpha)$, progesterone receptor (PR), or the human epidermal growth factor receptor2 (HER2/ERBB2) protooncogenic receptor are expressed. In many of these patients, treatment with anti-estrogens (e.g. aromatase inhibitors, tamoxifen, fulvestrant) and HER2-targeted agents has improved their survival significantly $(3,4)$. However, despite 
these treatments, it is common that some tumors develop de novo or acquire resistance to anti-estrogen and HER2targeted therapies, so these tumors can recur (5).

Regarding the $10 \%$ of breast cancer cases that are negative for ER $\alpha, P R$ and HER2, and therefore are called 'triplenegative', there is no clinically-proven type-specific drug target and only genotoxic chemotherapy is used (6).

Molecularly, based on gene expression, breast tumors can be classified into luminal A, luminal B, HER2-enriched and basal-like. Luminal A and B tumors express ER, while basallike are triple-negative tumors (7-9).

Given the incidence and the severity of the disease, new therapeutic targets need to be identified in order to treat breast cancer. Research in mechanisms that lead to resistance to establish therapies shows that promising targets for breast cancer treatment are histone deacetylases (HDAC) (10).

\section{HDAC Classification and Mechanism of Action}

Cell biology is based on the epigenetic modulation of gene expression $(11,12)$. The nucleosome is an organizing structure of DNA, of which packaging affects gene regulation. It consists of a DNA strand (about $200 \mathrm{bp}$ ) wound around an octameric core. This core consists of small, basic proteins which are called histones. Each core has two copies of every core histone ( $\mathrm{H} 2 \mathrm{~A}, \mathrm{H} 2 \mathrm{~B}, \mathrm{H} 3$, and H4) and one copy of H1. In total, the nucleosome looks like a string of beads. Histones form the inside core, whereas DNA is located outside of the core (13). However, the $\mathrm{N}$-terminal tails of histones extend outwards from the nucleosome protruding between the DNA coils. Histones are modified by substituents that covalently link to the side chains of certain amino acids in their N-terminal tails. They are modified by methylation, acetylation, phosphorylation and the opposite processes (14). These modifications alter the secondary DNA structure in order to induce or prevent access by transcription factors to gene promoter regions.

The reversible process of lysine acetylation at the $\varepsilon$-amino group of proteinogenic lysine residues is catalyzed by histone acetyl-transferases (HAT). Acetyl groups are removed by functional antagonists of HAT, histone deacetylases (HDACs) (15). In general, histone acetylation is associated with chromatin relaxation, given that it neutralizes the positive charge of lysine residues $(16,17)$. On the other hand, deacetylation leads to chromatin condensation, creating a structure called heterochromatin. In heterochromatin areas, transcription is repressed (18) (Figure 1).

Many different human HDACs have been identified. According to functional criteria and their homology with yeast proteins, HDACs are classified into four classes (19). These can be father divided into $\mathrm{Zn}^{2+}$-dependent classes (class I, II and IV) and NAD-dependent classes (class III). Class I consists of HDACs 1, 2, 3 and 8, whereas class IV has only one member HDAC11. Class II is divided into class IIa
(HDAC4, 5, 7, and 9) and class IIb (HDAC6 and 10) (20). Class III members are commonly known as sirtuins given the fact that they are homologous to silent information regulator 2 (SIR2) of Saccharomyces cerevisiae, and consist of SIRT1SIRT7 (Table I).

\section{HDAC Inhibitors as Anti-breast Cancer Agents}

For the above mentioned reason, histone acetylation and deacetylation have a great impact on chromatin remodeling and epigenetics (Figure 1). HDAC inhibitors have a potent role in cancer pathogenesis and progression. A number of reports indicate that in certain types of cancer, HDAC levels are increased (21-24).

Indicatively, we mention the activity of HDAC1. HDAC1 is a prototypical deacetylase, homolog of RPD3, which is yeast and fly HDAC1 ortholog (25) and was observed for the first time using a trapoxin affinity matrix (26). HDAC1 is expressed in many tumor types, such as in pre-malignant and malignant prostate lesions (27), primary human gastric cancer (28) and esophageal carcinomas (29). It was found that if small interfering double-strand RNA (siRNA) molecules suppressed HDAC1, the proliferation and the survival of carcinoma cells were inhibited in a concentration-dependent way (30). Moreover, overexpression of HDAC1 in breast cancer cell line model systems leads to silencing of $\operatorname{ER} \alpha$ gene and suppression of ER $\alpha$ protein (31). On the contrary, another study determined the levels of expression of the HDAC1 gene in malignant human breast tissue, using LightCycler-based quantitative real-time reverse transcriptase (RT)-polymerase chain reaction (PCR) analysis in 162 cases of invasive breast carcinoma. It seems that in patients over 50 years of age, with HER2-negative and ER $\alpha /$ PR-positive, tumors without axillary lymph node involvement, HDAC1 mRNA was highly expressed. There was a correlation between high levels of HDACl mRNA expression and a better prognosis in terms of both disease-free and overall survival (24). It is possible that there are other factors, for example multiprotein complexes, that are involved in the relation between HDAC1 and ER $\alpha$ expression $(32,33)$.

The aforementioned data are just an example of using HDACs as an anticancer target. HDAC inhibitors, enhance the acetylation of cellular proteins by blocking HDAC activity, (34). According to their chemical structure, HDAC inhibitors are classified into four classes: hydroxamates [e.g. suberoylanilide hydroxamic acid (SAHA)], benzamides (e.g. MS-275), cyclic peptides (e.g. romidepsin) and aliphatic acids (e.g. valproic acid). Alternatively, HDAC inhibitors can be classified by their specificity for HDAC subtypes or classes. For instance, SAHA and trichostatin A are pan-HDAC inhibitors, while MS-275 and romidepsin inhibit class I and valproic acid inhibits class I and IIa HDACs (35). 


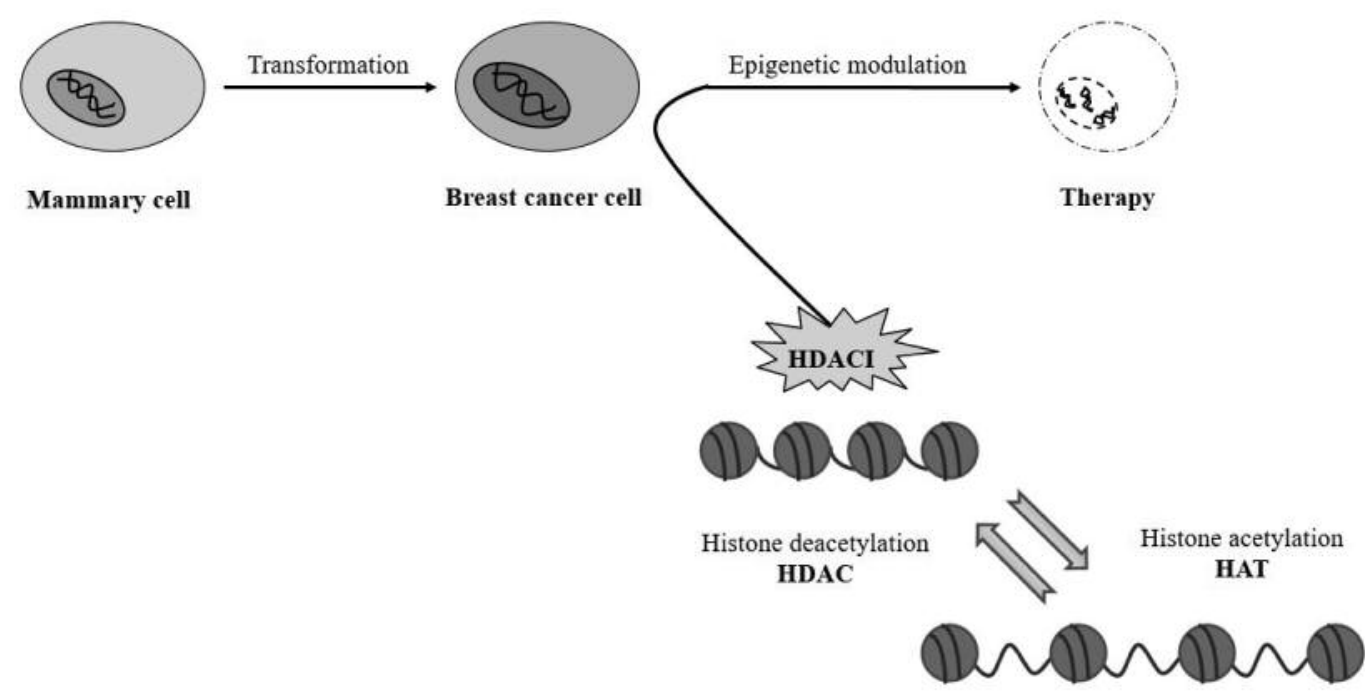

Figure 1. Therapeutic strategy using histone deacetylase inhibitors (HDACI). Lysine acetylation is catalyzed by histone acetyl transferase (HAT); acetyl groups are removed by histone deacetylaces (HDAC).

In general, HDAC inhibition leads to inhibition of tumor growth, and apoptosis of cancer cells, whereas normal tissue is not particularly affected. HDAC inhibitors have the ability to decompose and condense not only the histone-DNA complex, but also the acetylation status of non-histone proteins.

Clinical trials using HDAC inhibitors have been performed and their results indicate that HDAC inhibitors have antitumor activity $(14,36-40)$ and may be clinically beneficial. For example, SAHA/vorinostat and romidepsin were approved by the US Food and Drug Administration for the treatment of cutaneous T-cell lymphoma $(36,37)$ and peripheral T-cell lymphoma (38) respectively. In addition, panobinostat has demonstrated clinical success for the treatment of multiple myeloma (39). Today many inhibitors are being studied in advanced stages of clinical trials. With regard to breast cancer research, it has been shown that HDAC inhibitors exhibit potent activity in when combined with cytotoxic drugs, aromatase inhibitors, pro-drugs and ionizing radiation (41-44) (Table II).

SAHA. SAHA (vorinostat) is one of the most advanced smallmolecule pan-HDAC inhibitors. Its main mechanisms of action are changes in acetylating motif and downstream effects on apoptotic pathways (45). Preclinical data on MCF-7, MDA-MB 231, MDA-MB-435 and SKBr-3 breast cancer cell lines have shown growth inhibition caused by $\mathrm{G}_{1}$ and $\mathrm{G}_{2}-\mathrm{M}$ cycle phase arrest and apoptosis (46). In HER2-overexpressing breast cancer cell lines, SAHA not only facilitates apoptosis in a dose-dependent pattern, but also leads to heat-shock protein 90 (HSP90) acetylation. This acetylation causes dissociation of HSP90 from HER2 and as a result, HER2 is polyubiquitinylated and degraded (47).
Table I. Classification of histone deacetylases.

\begin{tabular}{lccc}
\hline $\mathrm{Zn}^{2+}$-dependent & & NAD-dependent \\
\hline Class I & Class II & Class III & Class IV \\
HDAC1, 2, 3,8 & $\begin{array}{c}\text { a: HDAC4, 5, 7,9 } \\
\text { b: HDAC6, 10 }\end{array}$ & HDAC11 & SIRT1-7 \\
\hline
\end{tabular}

SAHA was approved by the US Food and Drug Administration in October 2006 for the treatment of cutaneous T-cell lymphoma $(36,37)$. It has been used in clinical trials for treatment of a variety of solid and hematological tumors such as head and neck cancer (48), breast cancer (49) and Hodgkin lymphoma (50). However, the results of the phase II trial by the California Cancer Consortium against metastatic breast cancer are rather inconclusive. SAHA treatment appeared to have only modest clinical benefits. SAHA as monotherapy for patients with metastatic breast cancer with different molecular subtypes failed to meet the Response Evaluation Criteria In Solid Tumors response criteria (51) for adequate single-agent activity. However, due to its favorable toxicity and ease of administration it might be used as part of a combination therapy (for example co-treatment with paclitaxel and bevacizumab) (49).

Another trial in patients with advanced ER-positive breast cancer investigated co-treatment of SAHA and tamoxifen, an anti-estrogen, and showed that this combination was beneficial and reversed hormone resistance (41). In $40 \%$ of patients who had tried hormonal therapy and chemotherapy 
Table II. Histone deacetylase inhibitors and their action against breast cancer.

\begin{tabular}{ll}
\hline Substance & Action \\
\hline SAHA & Promotion of EMT of triple-negative breast cancer cells via HDAC8/FOXA1 signals \\
Trichostatin A & Inhibition of tumor growth, repression of cyclin D1 up-regulation \\
Syberoylbis-hydroxamic acid & p53-dependent way of apoptosis, regulation of p21, p27, BAX \\
Panobinostat & Restoration of ER $\alpha$ expression, inhibition of metastasis (co-treatment with letrozole) \\
Entinostat & Reversion of EMT, prevention of metastasis \\
Valproic acid & Anti-proliferative action, regulation of p21, cell-cycle arrest, apoptosis \\
Sodium butyrate & Apoptosis \\
SK7041 & Cytotoxicity, G2-M phase arrest, apoptosis \\
FTY720 & Reactivation of ER $\alpha$ expression, enhancement of hormonal therapy \\
Compound 2 & Anti-proliferative action, target HDAC8 \\
Scriptaid & Inhibition of tumor growth \\
YCW1 & Autophagic cell death, inhibition of BNIP3, cytoxicity (co-treatment with ionizing radiation) \\
SCA & Anti-proliferative action, degranulation of cytotoxic T-cells \\
Ferrocenyl & Inhibition of proliferation of ER $\alpha+$ and ER $\alpha-$ cells \\
\hline
\end{tabular}

EMT: Epithelial-mesenchymal transition; FOXA1: forkhead box protein A1; BAX: BCL2-associated X; ER $\alpha$ : estrogen receptor $\alpha$; FTY720: fingolimod; YCW1: octanedioic acid (3-(2-(5-methoxy-1H-indol-1-yl)ethoxy)phenyl)-amide N-hydroxyamide; BNIP3: BCL2/adenovirus E1B 19 $\mathrm{kDa}$ protein-interacting protein 3; SCA: santacruzamate A.

before, this combination led to tumor regression or stabilization of the disease. Given that the sample size was limited (43 patients), a randomized trial is needed in order to study the effects of this co-treatment over the efficacy of tamoxifen alone. Moreover, in presence of SAHA, tamoxifen induces apoptosis rather than antiproliferative effect, probably because of HDAC2 inhibition (52). Researchers suggested that new studies associated with acetylation bioassays and HDAC2 expression in tumors is required in order to validate the antitumor efficacy of hormonal therapy and HDAC2 inhibitors (41).

A research studied the activity of SAHA on triple-negative breast cancer, using MDA-MB-231 and BT-549 cells (53). The results revealed that SAHA promotes the in vitro trafficking of triple-negative breast cancer cells via induction of epithelial-mesenchymal transition (EMT) phenotype. This phenotype is known to contribute to cancer recurrence and metastasis (54). It should be noted that during SAHA treatment, expression and subcellular translocation of EMTrelated transcription factors (55), zinc finger protein SNAI1 (SNAIL), zinc finger protein SNAI2 (SLUG), basic helixloop-helix transcription factor twist-related protein (TWIST) and zinc finger E-box-binding homeobox (ZEB) did not change. This indicates that EMT-related transcription factors are not involved in SAHA-induced EMT.

Forkhead box A1 (FOXA1) mediates SAHA-induced EMT in triple-negative breast cancer cells (53). FOXA1 is a growth inhibitor that can be used as a prognostic factor in human breast cancer (56). At the beginning of SAHA treatment, FOXA1 expression decreased and its nuclear translocation was down-regulated, in a time-dependent manner. Subsequently, SAHA-induced EMT was weakened by overexpression of
SNAIL. Moreover, in human triple-negative cell lines MDAMB-231 and BT-549, SAHA-induced down-regulation of FOXA1 transcription was attenuated by silencing of HDAC8, but not HDAC6 (53). Studies claimed that SAHA activity is mediated by HDAC6 and HDAC $8(57,58)$. HDAC 8 is a very unique class I HDAC given the fact that it lacks the conserved C-terminal domain (59) and its expression profile is different from those of HDACs 1-3 (60). HDAC8 knockdown does not influence histone acetylation (61), but it has been claimed that it could act at certain promoter sites of FOXA (53).

Trichostatin A. Trichostatin A (TSA) is an antifungal antibiotic and is found in cultured mammalian cells and in fractionated cell nuclear extracts at low nanomolar concentrations. In general, as an HDAC inhibitor, TSA not only represses HDAC activity, but also arrests the cell cycle in $G_{1}$ and $G_{2}$ phase, induces cell differentiation and the reversion of transformed cells in culture (62). An early study revealed TSA to be a potent inhibitor of tumor growth of human breast cancer cells. Furthermore, ER $\alpha$-positive breast cancer cell lines were up to 10 times more sensitive to growth inhibition than ER $\alpha$ negative cell lines (63).

In another study, ER-negative human breast cancer cells were treated with TSA and RT-PCR results showed that ER mRNA was re-expressed in a dose- and time-dependent manner, without changes in $\mathrm{ER} \alpha \mathrm{CpG}$ island methylation. In MDA-MB-231 cells, these results correlated with sensitivity of the ER locus to DNase I. Treatment in mouse models with TSA in combination with the hypomethylating agent or 5-aza2'-deoxycytidine (AZA), inhibited the progress of the tumor and indicated better results compared with TSA, and AZA alone (64). 
Alao et al. found that in breast cancer cells, TSA affects cyclin D1. It seems that TSA represses cyclin D1 upregulation. This repression was found in both ER $\alpha$-dependent and-independent cell lines. In particular, in the ER $\alpha$-positive MCF-7 breast cancer cell line, in addition to the inhibition of $\mathrm{ER} \alpha$ and cyclin D1 transcription, TSA led to ubiquitindependent proteasomal degradation of cyclin D1 and arrested the cell cycle in G1-S phase. However, in the ER $\alpha$-negative MDA-MB-231 breast cancer cell line, while TSA led to degradation of cyclin D1, it did not particularly affect its transcription and led to $\mathrm{G}_{2}-\mathrm{M}$ phase arrest. These results indicate that both cyclin D1 degradation and inhibition of ER $\alpha$ transcription determine the sensitivity of ER $\alpha$-positive breast cancer cells to growth inhibition by TSA (65).

Suberoylbis-hydroxamic acid. Suberoylbis-hydroxamic acid (SBHA) is a HDAC inhibitor that has a similar structure to SAHA and TSA. It has shown anticancer activity against many types of tumors, such as medullary thyroid and lung cancer $(66,67)$. Studies in both A549 lung cancer cells and MCF-7 breast cancer cells indicated that SBHA treatment induced a significant level of apoptosis $(67,68)$. Specifically, SBHA seemed to induce p53-dependent apoptosis of MCF-7 breast cancer cells. Another investigation studied the association of SBHA with cancer cell proliferation and apoptosis. The results revealed that treatment with SBHA not only inhibited MCF-7 cell proliferation, but also induced apoptotic cell death in a concentration-dependent manner. The cell cycle was arrested at $\mathrm{G}_{0}-\mathrm{G}_{1}$ phase. In addition, levels of p21 (cyclin-dependent kinase inhibitor 1 (WAF1)) and p27 (kinesin-like protein (KIP1)) proteins increased, as did apoptosis regulator BCL-2-like protein 4 (BAX) expression, whereas apoptosis regulator B-cell lymphoma 2 (BCL2) expression was reduced (69). p21 and p27 are inhibitors of cyclin-dependent kinases, hence they are involved in cellcycle control (70) and appear to suppress MCG-7 cell proliferation in vitro (71). $B A X$ is a pro-apoptotic member of the BCL2 family and a downstream target gene of p53 that mediates p53-dependent apoptosis (72). Lack of BAX is associated with p53-induced apoptosis in neurons (73). Research on MCF-7 cells treated with SBHA showed shrinkage, chromatin condensation and nuclear fragmentation with Hoechst 33258 staining. However, the antiproliferative potency of SBHA appeared to be less than that of SAHA (69).

Panobinostat. Panobinostat (LBH589) is a pan-HDAC inhibitor recently approved for treatment of multiple myeloma with tumor progression after immunomodulating agents and bortezomib. It expresses its inhibitory activity against solid tumors, such as lung, breast, ovarian cancer and multiple myeloma (74). According to one study, in ER-negative human breast cancer lines MDA-MB-231 and MDA-MB-435 treated with panobinostat for 24 hours, ER $\alpha$ mRNA and protein expression were restored, whereas $\mathrm{CpG}$ island at the ER promoter was not demethylated. After at least 96 hours from termination of panobinostat treatment, the expression of ER $\alpha$ mRNA was maintained. Chromatin immunoprecipitation analysis showed panobinostat treatment released DNA (cytosine-5)-methyltransferase 1 (DNMT1), HDAC1, and the H3 lysine 9 (H3-K9) methyltransferase SUV39H1 from the ER promoter. There was a connection between these alterations and active chromatin formation. This formation led to an increase of acetylated $\mathrm{H} 3$ and $\mathrm{H} 4$, a decrease in methylated H3-K9 and false binding of heterochromatin protein 1 (HP1 alpha) at the promoter (75).

Kubo et al. studied panobinostat in combination to aromatase inhibitors. They used aromatase inhibitor-resistant breast cancer cell lines and tumors and found that by stopping the cell cycle at $\mathrm{G}_{2}-\mathrm{M}$ phase and by inducing apoptosis, growth of aromatase inhibitor-resistant cells was prevented in vitro and in vivo by panobinostat. In addition, while resistance to aromatase inhibitor is reflected by the overexpression of Nuclear factor -kappa-B p105 subunit (NF-kB1), with treatment with parobinostat, the level of NF-kB1 in tumors fell $(76,77)$. Furthermore, a recent phase I clinical trial in patients with metastatic breast cancer tested the safety and efficacy of the combined treatment of panobinostat and the aromatase inhibitor letrozole. This trial tested the safety and efficacy of this co-treatment. Researchers found that this co-treatment was safe and recommended a tolerable dose for the phase II clinical trial (panobinostat at $20 \mathrm{mg}$ orally 3 times weekly and oral letrozole at $2.5 \mathrm{mg}$ daily) (78). These data indicate that panobinostat may soon have a role in the treatment of metastatic breast cancer in the future.

Entinostat. Tumor cells undergo EMT which enables spread from the primary site. This transition makes a cancer cell's phenotype invasive (79), allowing establishment of metastases which leads to mortality (80). Recent data show that escape from the primary site may be achieved by a subset of cells within a breast tumor. These cells are termed as tumorinitiating cells (TICs). TICs produce progenitor cells, which cannot self-renew, but may comprise the greater part of the tumor (54). Entinostat (MS-275), a selective inhibitor of class I HDACs, reverses the EMT phenotype. This reversion is a result of epigenetic repression of E-cadherin $(81,82)$. A new study showed that treatment with entinostat reduced the level of TICs in triple-negative breast cancer cells. These results may indicate that entinostat can prevent development of metastasis (43).

HDACs may in general also influence non-histone proteins, such as Hypoxia-inducible factor 1-alpha (HIF1 $\alpha)$, which participate in drug resistance, EMT and development of TICs (83). Given the fact that HDAC inhibitors are related to EMT and TICs, a number of studies have been performed. In particular, valproic acid and SAHA (vorinostat) appeared to 
reduce the population of TICs in breast cancer cell lines (84). TSA seemed to induce a TIC phenotype in head and neck cancer cells and increased EMT (85). However, as mentioned, valproic acid, SAHA and TSA block class I and II HDACs, whereas entinostat specifically blocks class I HDACs. It is understandable that further research is needed on the regulation of EMT and TICs by specific HDACs in order to identify potential clinical benefits.

Yardley et al. conducted a phase II, double-blind, placebocontrolled study of the aromatase inhibitor exemestane with and without entinostat in postmenopausal women with metastatic, ER-positive breast cancer. In this trial, 134 patients with advanced ER-positive breast cancer resistant to aromatase inhibition received entinostat combined with exemestane. Cotreatment enhanced the progression-free survival from 2.3 to 4.3 months and the median overall survival from 19.8 to 28.1 months compared with exemestane alone. Further research is needed to validate this result (86).

Valproic Acid. Valproic acid causes hyperacetylation of the $\mathrm{N}$ terminal tails of $\mathrm{H} 3$ and $\mathrm{H} 4$ in vitro and in vivo and inhibits HDAC activity, probably by binding to the catalytic center and blocking the access of the substrate (87). It has been used for treatment of epilepsy and bipolar disorder $(88,89)$. Valproic acid is a potent inhibitor of class I HDACs, but it also inhibits class II HDACs (90). Additionally, by inducing gene targeting of cyclin-dependent kinase inhibitor p21 (WAF1), valproic acid influences differentiation and has antiproliferative effects (91). p21 regulates cell-cycle progression, given the fact that is involved in both $\mathrm{G}_{1}-\mathrm{S}$ and the $\mathrm{G}_{2}-\mathrm{M}$ transition. Valproic acid is found to suppress the growth of ER-positive breast cancer cells at a lower dose than that required for ER-negative cells (92). Moreover, the extent of cell growth suppression by valproic acid is not related to estrogen sensitivity (93).

Studies in HER2-negative breast cancer cell lines indicated that valproic acid has antiproliferative activity (92-94). In studies of HER2-overexpressing breast cancer cells, at a clinically achievable dose of $1 \mathrm{mM}$, valproic acid reduced proliferation by cell-cycle arrest and induction of apoptosis; moreover HER2-overexpressing breast cancer cells were more sensitive to valproic acid treatment than HER2-negative ones (95). This antiproliferative activity of valproic acid seems to be a result of HSP90 dysfunction, which hyperacetylates HSP70. The hyperacetylation of HSP70 affects HER2 protein, which is a client protein of HSP90. HSPs are highly conserved molecular chaperones. Specifically HSP90 controls the intracellular trafficking and folding of some cellular proteins. Dysfunction of HSP90 destabilizes and degrades HSP90 client proteins and leads to apoptosis (96).

Furthermore, Mawatari et al. used immunohistochemical techniques and terminal deoxynucleotidyl transferase dUTP nick end labeling assay and found that valproic acid induced apoptosis of SKBR3 cells by activating caspase-3, which induces apoptosis in the form of cleaved caspase-3 (95). Recently, co-treatment of valproic acid and the prodrug capecitabine, which is commonly used for metastatic breast cancer in different settings, resulted in antiproliferative and pro-apoptotic effects on breast cancer cells both in vitro and in vivo, and this might become an innovative antitumor strategy against metastatic breast cancer (97).

Sodium Butyrate. Sodium butyrate, as member of the HDAC inhibitor family, was shown to exhibit an effective anticancer ability (98). It leads to relaxation of chromatin structure, allowing easier access to transcription-related proteins. These abilities made sodium butyrate a widespread treatment against many types of solid tumor $(99,100)$. In addition, studies in MCF-7 cells demonstrated that sodium butyrate has a doseand time-dependent anti-proliferative effect (101).

Another study treated MCF-7 cells with sodium butyrate in order to correlate it with cell apoptosis and structural alterations. It was found that sodium butyrate suppressed MCF-7 cell viability in a concentration- and durationdependent manner. Moreover, it indicated that sodium butyrate treatment reduced BCL2 expression in MCF-7 cells. This evidence supported the correlation of sodium butyrate effects with cell apoptosis, which was observed previously in other cell types $(102,103)$. As apoptotic cells exhibit morphological alterations (104), microscopy revealed cell shrinkage, rounding, large amounts of heterochromatin, chromatin condensation, apoptotic nuclei, minimization of mitochondria and incredibly high cytoplasmic vacuolization (balloon-like vacuoles) in sodium butyrate-treated cells in comparison with control (105).

SK7041. SK7041 belongs to a class of synthetic HDAC inhibitors which are composed of hybridization of TSA and MS-275. In general, the structure of HDAC inhibitors consists of a functional moiety, a cap, and a linker, which connects the cap and functional moiety. The TSA functional moiety is hydroxamic acid. TSA has powerful inhibitory activity at nanomolar concentrations, but is unstable and has low bioavailability (63). MS-275, a synthetic benzamide derivative, consists of a pyridyl ring cap structure and has better physicochemical properties than TSA, but its HDACinhibitory activity is low at micromolar concentrations (106). Researchers created a hybrid in order to keep the high inhibitory activity of TSA and enhance its physicochemical properties. For this reason, the cap structure of TSA was replaced with the pyridyl ring of MS-275.

In one study, SK-7041 was evaluated on breast (MDA-MB231, MCF-7, and SK-BR-3) and lung (A549, NCI-H23, and NCI-H1299) cancer cell lines. It was found that not only was SK-7041 cytotoxic in breast and lung cancer cell lines, but it also showed more potent cytotoxicity than SAHA. It induced histone acetylation and had an antiproliferative effect on these cell lines. 
These effects were the result of G2-M phase arrest and, to some extent, $\mathrm{G}_{1}$-phase arrest, therefore SK-7041 treatment appears to provoke apoptotic cell death (107). This evidence is supported by other reports on treatment with SK-7041 in gastric and pancreatic cancer cell lines $(108,109)$. Furthermore, SK-7041 was found to inhibit cell proliferation more selectively in cancer lines than in normal human cell lines (107).

FTY720. FTY720 (fingolimod), a sphingosine analog, is a prodrug approved by the US Food and Drug Administration for the treatment of multiple sclerosis. A study showed that FTY720 is phosphorylated in the nucleus of both ER-positive and ER-negative breast cancer cells by nuclear sphingosine kinase 2. Nuclear FTY720-phosphate (P) is a class I HDAC inhibitor. FTY720-P, as a powerful inhibitor, is highly involved in histone acetylation and in gene expression.

A recent study which investigated ER $\alpha$-negative human and mouse breast cancer cells showed that FTY720 induced the re-expression of silenced ER $\alpha$. In this study, FTY720 was given orally to mice in clinically accepted doses and, as a result, HDAC activity decreased and the evolution and development of breast tumors were diminished (110). They also found that the inhibitor sensitizes cells to tamoxifen and, in comparison with other HDAC inhibitors (e.g. SAHA), it enhanced the sensitivity to the treatment (110).

$N$-(2-Hydroxyphenyl)-2propylpentanamide. $N$-(2-Hydroxyphenyl)-2propylpentanamide is an aryl derivative of valproic acid. These derivatives are produced by combining valproic acid and the arylamine core of SAHA with different substituents at its carboxyl group. $N$-(2-Hydroxyphenyl)2 propylpentanamide was the most promising compound among other derivatives which were submitted to docking simulations. In vitro studies showed that it was the best anticancer agent against HeLa, rhabdomyosarcoma and breast cancer cell lines and in particular, triple-negative breast cancer cells. This compound seems to target HDAC8. In addition, in vitro studies showed that in comparison with valproic acid, $N$-(2-Hydroxyphenyl)-2propylpentanamide inhibited cancer cell proliferation at a much lower concentration (111).

Scriptaid. Scriptaid is a member of the hydroxamic class of HDAC inhibitors, so it is similar to TSA (112). Protein expression and ER mRNA function are influenced by the activity of HDAC inhibitor Scriptaid. Specifically, in MDA231, MDA-MB-435, and Hs578t ER cell lines, not only was ER function restored, but tumor growth was also inhibited. Furthermore, given the fact that dose-dependent re-expression of PR was observed, it seemed that ER functioned. Acetylation of $\mathrm{H} 3$ and $\mathrm{H} 4$ histone tails was also increased. Cotreatment with Scriptaid and methyltransferase inhibitor AZA gave better results in comparison with Scriptaid, or AZA alone. We can assume that in regard to ER-negative human breast cancer cells, Scriptaid could have clinical benefits in the dissection of the components of the repressive complex at the methylated ER locus (113).

YCW1. Octanedioic acid (3-(2-(5-methoxy-1H-indol1yl)ethoxy)phenyl)-amide $N$-hydroxyamide (YCW1) is a novel HDAC inhibitor which was developed using structurebased analyses $(114,115)$. YCW1 activity was investigated in the murine triple-negative breast cancer cell line $4 \mathrm{~T} 1$ and the human triple-negative breast cancer cell line MDA-MB-231. The authors particularly tested the co-treatment of YCW1 and ionizing radiation (IR) for its antitumor effects. They found that this combination led to an increase of autophagy and endoplasmic reticulum stress, thereby acting as a cytotoxic against triple-negative breast cancer cells (44). Moreover, in comparison with the inhibitory activity of SAHA, YCW1 significantly enhanced toxicity.

It is known that in patients with triple-negative breast cancer, positive BCL2 expression is associated with poor survival and lower sensitivity to chemotherapy (116). BCL2/adenovirus E1B $19 \mathrm{kDa}$ protein-interacting protein 3 (BNIP3) is a member of the BCL2 subfamily and is associated with death-inducing mitochondrial proteins (117) and autophagy $(118,119)$. BNIP3 is not expressed in normal breast tissue but is up-regulated in breast cancer cells (120). In Chiu et al.'s study that was mentioned above, BNIP3 levels were significantly decreased in $4 \mathrm{~T} 1$ cells that were cotreated with YCW1 and IR in comparison with those treated with YCW1 or IR alone. The authors claimed that this downregulation of BNIP3 enhanced the antitumor effects of IR and YCW1 by inducing autophagic cell death and cytotoxicity. These results were also confirmed in an orthotopic breast cancer mouse model. Therefore, Chiu et al. supported the hypothesis that in triple-negative breast cancer, co-treatment with IR and YCW1 induced autophagic cell death, through the inhibition of BNIP3 (44).

Santacruzamate A. The Panamanian marine cyanobacterium Symploca sp. produces a natural bioactive product, santacruzamate A (SCA). SCA seems to act as a HDAC inhibitor and consists of structural domains which also exist in SAHA. In one study, Gromek et al. used 40 SCA analogs which were synthesized with alterations in the zinc-binding group, cap terminus, and linker region, three structural motifs that appear in the majority of HDAC inhibitors. Analogs were categorized by their cap. It was found that the proliferation of MCF-7 breast cancer cells was inhibited in two group analogs and other analogs seemed to influence the degranulation of cytotoxic T-cells (121).

Ferrocenyl. Selective ER modulators have many advantages in the treatment of hormone-responsive breast cancer. 
However, they are ineffective for ER-negative breast cancer. In recent research, a series of dual-acting ER and HDAC inhibitors were designed with incorporation of a ferrocenyl moiety, leading to novel hybrid ferrocenyl conjugates (FcOBHS-HDAC inhibitors) against breast cancer. These ferrocenyl conjugates can inhibit both the proliferation of $\mathrm{ER} \alpha$-positive (MCF-7) and ER-negative breast cancer cells (MDA-MB-231), and are a very promising strategy against breast cancer (122).

\section{Conclusion}

HDAC inhibitors represent the first successful epigenetic therapy against cancer. They seem to be clinically beneficial in subtypes of hematological malignancies. On the contrary, their efficacy against solid tumors is unclear (123). Despite the positive results in some pre-clinical trials, most HDAC inhibitors used as single agents failed to achieve treatment as a single therapy against solid tumors (124). For instance, use of SAHA as monotherapy in 14 patients with metastatic breast cancer failed to demonstrate adequate single-agent activity (49). As such, at the moment, clinical trials tend to combine HDAC inhibitors with cytotoxics, aromatase inhibitors, prodrugs and chemotherapy (41-44) in order to enhance their effects against tumors.

In a significant proportion of breast cancers, the ER $\alpha$ gene is abnormally methylated at its $\mathrm{CpG}$ island. As a result, the expression of ER $\alpha$ gene is inhibited. Consequently, researchers started to study how HDAC inhibitors reverse resistance to anti-estrogen therapies in vitro. It was found that HDAC inhibitors can restore sensitivity to ER in endocrine-resistant and triple-negative breast cancer cell lines (125-127).

Except for a phase II trial of SAHA (49), other investigators occurred another phase II trial. Munster et al. treated patients with ER-positive endocrine-resistant metastatic disease with SAHA and tamoxifen. This co-treatment induced an objective response rate of $19 \%$, clinical benefit rate of $40 \%$ and median response duration of 10.3 months (41). Another trial that studied co-treatment of entinostat and exemestane in patients with advanced ER-positive breast cancer resistant to aromatase inhibition showed that progression-free survival improved compared with exemestane/placebo (86). Moreover, in patients with metastatic breast cancer, researchers investigated the combination of panobinostat and letrozole and we attend phase II trial so panobinostat would be approved for treatment of metastatic breast cancer (78).

It is understandable that the identification of new targets in breast cancer is very promising. Future therapy advances will likely include combination treatment using HDAC inhibitors and chemotherapy or other inhibitors. By combining therapeutics, we can simultaneously target multiple oncogenic signaling pathways and overcome resistance.

\section{References}

1 DeSantis CE, Bray F, Ferlay J, Lortet-Tieulent J, Anderson BO and Jemal A: International variation in female breast cancer incidence and mortality rates. Cancer Epidemiol Biomarkers Prev 24: 1495-1506, 2015.

2 Nyante SJ, Lee SS, Benefield TS, Hoots TN and Henderson LM: The association between mammographic calcifications and breast cancer prognostic factors in a population-based registry cohort. Cancer 2016. doi: 10.1002/cncr.30281

3 Rexer BN and Arteaga CL: Intrinsic and acquired resistance to HER2-targeted therapies in HER2 gene-amplified breast cancer: mechanisms and clinical implications. Crit Rev Oncog 17: 116,2012

4 Giuliano M, Schifp R, Osborne CK and Trivedi MV: Biological mechanisms and clinical implications of endocrine resistance in breast cancer. Breast 20(Suppl 3): S42-49, 2011.

5 Tryfonidis K, Zardavas D, Katzenellenbogen BS and Piccart M: Endocrine treatment in breast cancer: Cure, resistance and beyond. Cancer Treat Rev 50: 68-81, 2016.

6 Curtis C, Shah SP, Chin SF, Turashvili G, Rueda OM, Dunning MJ, Speed D, Lynch AG, Samarajiwa S, Yuan Y, Gräf S, Ha G, Haffari G, Bashashati A, Russell R, McKinney S; METABRIC Group, Langerød A, Green A, Provenzano E, Wishart G, Pinder S, Watson P, Markowetz F, Murphy L, Ellis I, Purushotham A, Børresen-Dale AL, Brenton JD, Tavaré S, Caldas C and Aparicio $\mathrm{S}$ : The genomic and transcriptomic architecture of 2,000 breast tumours reveals novel subgroups. Nature 486: 346-352, 2012.

7 Sorlie T, Perou CM, Tibshirani R, Aas T, Geisler S, Johnsen H, Hastie T, Eisen MB, van de Rijn M, Jeffrey SS, Thorsen T, Quist H, Matese JC, Brown PO, Botstein D, Lønning PE and BørresenDale AL: Gene expression patterns of breast carcinomas distinguish tumor subclasses with clinical implications. Proc Natl Acad Sci USA 98: 10869-10874, 2001.

8 Cho N: Molecular subtypes and imaging phenotypes of breast cancer. Ultrasonography 35: 281-2888, 2016.

9 Bertucci F, Finetti P, Cervera N, Esterni B, Hermitte F, Viens P and Birnbaum D: How basal are triple-negative breast cancers? Int J Cancer 123: 236-240, 2008.

10 Hosford SR and Miller TW: Clinical potential of novel therapeutic targets in breast cancer: CDK4/6, Src, JAK/STAT, PARP, HDAC, and PI3K/AKT/mTOR pathways. Pharmgenomics Pers Med 7: 203-215, 2014.

11 Marks DL, Olson RL and Fernandez-Zapico ME: Epigenetic control of the tumor microenvironment. Epigenomics 2016. doi:10.2217/epi-2016-0110

12 Jones P: The cancer epigenome. Genome 56: 540-541, 2013.

13 Rando OJ and Ahmad K: Rules and regulation in the primary structure of chromatin. Curr Opin Cell Biol 19: 250-256, 2007.

14 Woo YM: Epigenetic Regulation in Cystogenesis. Adv Exp Med Biology 933: 59-68, 2016.

15 Kuo MH and Allis CD: Roles of histone acetyltransferases and deacetylases in gene regulation. Bioessays 20: 615-626, 1998.

16 Inche AG and La Thangue NB: Chromatin control and cancerdrug discovery: realizing the promise. Drug Discov Today 11: 97109, 2006.

17 Kouzarides T: Chromatin modifications and their function. Cell 128: 693-705, 2007.

18 Haberland M, Montgomery RL and Olson EN: The many roles of histone deacetylases in development and physiology: 
implications for disease and therapy. Nat Rev Genet 10: 32-42, 2009.

19 Trapp J and Jung M: The role of NAD+ dependent histone deacetylases (sirtuins) in ageing. Curr Drug Targets 7: 1553-1560, 2006.

20 Olzscha H, Sheikh S and La Thangue NB: Deacetylation of chromatin and gene expression regulation: a new target for epigenetic therapy. Crit Rev Oncog 20: 1-17, 2015.

21 Li A, Liu Z, Li M, Zhou S, Xu Y, Xiao Y and Yang W: HDAC5, a potential therapeutic target and prognostic biomarker, promotes proliferation, invasion and migration in human breast cancer. Oncotarget 7: 37966-37978, 2016.

22 Krusche CA, Wülfing P, Kersting C, Vloet A, Böcker W, Kiesel L, Beier HM and Alfer J: Histone deacetylase-1 and -3 protein expression in human breast cancer: a tissue microarray analysis. Breast Cancer Res Treat 90: 15-23, 2005.

23 Stojanovic N, Hassan Z, Wirth M, Wenzel P, Beyer M, Schäfer C, Brand P, Kroemer A, Stauber RH, Schmid RM, Arlt A, Sellmer A, Mahboobi S, Rad R, Reichert M, Saur D, Krämer OH and Schneider G: HDAC1 and HDAC2 integrate the expression of p53 mutants in pancreatic cancer. Oncogene 2016. doi: 10.1038/onc.2016.344

24 Zhang Z, Yamashita H, Toyama T, Sugiura H, Ando Y, Mita K, Hamaguchi M, Hara Y, Kobayashi S and Iwase H: Quantitation of HDAC1 mRNA expression in invasive carcinoma of the breast*. Breast Cancer Res Treat 94: 11-16, 2005.

25 Taunton J, Hassig CA and Schreiber SL: A mammalian histone deacetylase related to the yeast transcriptional regulator Rpd3p. Science 272: 408-411, 1996.

$26 \mathrm{Ng} \mathrm{HH}$ and Bird A: Histone deacetylases: silencers for hire. Trends Biochem Sci 25: 121-126, 2000.

27 Halkidou K, Gaughan L, Cook S, Leung HY, Neal DE and Robson CN: Upregulation and nuclear recruitment of HDAC1 in hormone-refractory prostate cancer. Prostate 59: 177-189, 2004.

28 Kim JH, Choi YK, Kwon HJ, Yang HK, Choi JH and Kim DY: Down-regulation of gelsolin and retinoic acid receptor beta expression in gastric cancer tissues through histone deacetylase 1. J Gastroenterol Hepatol 19: 218-224, 2004.

29 Toh Y, Yamamoto M, Endo K, Ikeda Y, Baba H, Kohnoe S, Yonemasu H, Hachitanda Y, Okamura T and Sugimachi K: Histone $\mathrm{H} 4$ acetylation and histone deacetylase 1 expression in esophageal squamous cell carcinoma. Oncol Rep 10: 333-338, 2003.

30 Glaser KB, Li J, Staver MJ, Wei RQ, Albert DH and Davidsen SK: Role of class I and class II histone deacetylases in carcinoma cells using siRNA. Biochem Biophys Res Commun 310: 529536, 2003.

31 Kawai H, Li H, Avraham S, Jiang $\mathrm{S}$ and Avraham HK: Overexpression of histone deacetylase HDAC1 modulates breast cancer progression by negative regulation of estrogen receptor alpha. Int J Cancer 107: 353-358, 2003.

32 Khochbin S, Verdel A, Lemercier C and Seigneurin-Berny D: Functional significance of histone deacetylase diversity. Curr Opin Genet Dev 11: 162-166, 2001.

33 Meehan WJ, Samant RS, Hopper JE, Carrozza MJ, Shevde LA, Workman JL, Eckert KA, Verderame MF and Welch DR: Breast cancer metastasis suppressor 1 (BRMS1) forms complexes with retinoblastoma-binding protein 1 (RBP1) and the MSIN3 histone deacetylase complex and represses transcription. J Biol Chem 279: 1562-1569, 2004.
34 New M, Olzscha H and La Thangue NB: HDAC inhibitor-based therapies: Can we interpret the code? Mol Oncol 6: 637-656, 2012.

35 Marks PA: The clinical development of histone deacetylase inhibitors as targeted anticancer drugs. Expert Opin Investig Drugs 19: 1049-1066, 2010.

36 Mann BS, Johnson JR, He K, Sridhara R, Abraham S, Booth BP, Verbois L, Morse DE, Jee JM, Pope S, Harapanhalli RS, Dagher R, Farrell A, Justice R and Pazdur R: Vorinostat for treatment of cutaneous manifestations of advanced primary cutaneous T-cell lymphoma. Clin Cancer Res 13: 2318-2322, 2007.

37 Marks PA: Discovery and development of SAHA as an anticancer agent. Oncogene 26: 1351-1356, 2007.

38 Barbarotta L and Hurley K: Romidepsin for the treatment of peripheral T-Cell lymphoma. J Adv Pract Oncol 6: 22-36, 2015.

39 Libby EN, Becker PS, Burwick N, Green DJ, Holmberg L and Bensinger WI: Panobinostat: a review of trial results and future prospects in multiple myeloma. Expert Rev Hematol 8: 9-18, 2015.

40 Damaskos C, Valsami S, Spartalis E, Antoniou EA, Tomos P, Karamaroudis S, Zoumpou T, Pergialiotis V, Stergios K, Michaelides C, Kontzoglou K, Perrea D, Nikiteas N and Dimitroulis D: Histone deacetylase inhibitors: a novel therapeutic weapon against medullary thyroid cancer? Anticancer Res 36: 5019-5024, 2016.

41 Munster PN, Thurn KT, Thomas S, Raha P, Lacevic M, Miller A, Melisko M, Ismail-Khan R, Rugo H, Moasser M and Minton SE: A phase II study of the histone deacetylase inhibitor vorinostat combined with tamoxifen for the treatment of patients with hormone therapy-resistant breast cancer. Br J Cancer 104: 18281835, 2011.

42 Chen S, Ye J, Kijima I and Evans D: The HDAC inhibitor LBH589 (panobinostat) is an inhibitory modulator of aromatase gene expression. Proc Natl Acad Sci USA 107: 11032-11037, 2010.

43 Schech A, Kazi A, Yu S, Shah P and Sabnis G: Histone deacetylase inhibitor entinostat inhibits tumor-initiating cells in triple-negative breast cancer cells. Mol Cancer Ther 14: 1848$1857,2015$.

44 Chiu HW, Yeh YL, Wang YC, Huang WJ, Ho SY, Lin P and Wang YJ: Combination of the novel histone deacetylase inhibitor YCW1 and radiation induces autophagic cell death through the downregulation of BNIP3 in triple-negative breast cancer cells in vitro and in an orthotopic mouse model. Mol Cancer 15: 46, 2016.

45 Finnin MS, Donigian JR, Cohen A, Richon VM, Rifkind RA, Marks PA, Breslow R and Pavletich NP: Structures of a histone deacetylase homologue bound to the TSA and SAHA inhibitors. Nature 401: 188-193, 1999.

46 Munster PN, Troso-Sandoval T, Rosen N, Rifkind R, Marks PA and Richon VM: The histone deacetylase inhibitor suberoylanilide hydroxamic acid induces differentiation of human breast cancer cells. Cancer Res 61: 8492-8497, 2001.

47 Bali P, Pranpat M, Swaby R, Fiskus W, Yamaguchi H, Balasis M, Rocha K, Wang HG, Richon V and Bhalla K: Activity of suberoylanilide hydroxamic acid against human breast cancer cells with amplification of HER2. Clin Cancer Res 11: 6382-6389, 2005.

48 Blumenschein GR Jr, Kies MS, Papadimitrakopoulou VA, Lu C, Kumar AJ, Ricker JL, Chiao JH, Chen C and Frankel SR: Phase II trial of the histone deacetylase inhibitor vorinostat (Zolinza, suberoylanilide hydroxamic acid, SAHA) in patients with recurrent and/or metastatic head and neck cancer. Invest New Drugs 26: 81-87, 2008. 
49 Luu TH, Morgan RJ, Leong L, Lim D, McNamara M, Portnow J, Frankel P, Smith DD, Doroshow JH, Wong C, Aparicio A, Gandara DR and Somlo G: A phase II trial of vorinostat (suberoylanilide hydroxamic acid) in metastatic breast cancer: a California Cancer Consortium study. Clin Cancer Res 14: 7138-7142, 2008.

50 O'Connor OA, Heaney ML, Schwartz L, Richardson S, Willim R, MacGregor-Cortelli B, Curly T, Moskowitz C, Portlock C, Horwitz S, Zelenetz AD, Frankel S, Richon V, Marks P and Kelly WK: Clinical experience with intravenous and oral formulations of the novel histone deacetylase inhibitor suberoylanilide hydroxamic acid in patients with advanced hematologic malignancies. J Clin Oncol 24: 166-173, 2006.

51 Therasse P, Arbuck SG, Eisenhauer EA, Wanders J, Kaplan RS, Rubinstein L, Verweij J, Van Glabbeke M, van Oosterom AT, Christian MC and Gwyther SG: New guidelines to evaluate the response to treatment in solid tumors. European Organization for Research and Treatment of Cancer, National Cancer Institute of the United States, National Cancer Institute of Canada. J Natl Cancer Inst 92: 205-216, 2000.

52 Marchion DC, Bicaku E, Turner JG, Schmitt ML, Morelli DR and Munster PN: HDAC2 regulates chromatin plasticity and enhances DNA vulnerability. Mol Cancer Ther 8: 794-801, 2009.

$53 \mathrm{Wu} \mathrm{S}$, Luo Z, Yu PJ, Xie H and He YW: Suberoylanilide hydroxamic acid (SAHA) promotes the epithelial-mesenchymal transition of triple-negative breast cancer cells via HDAC8/FOXA1 signals. Biol Chem 397: 75-83, 2016.

54 Mani SA, Guo W, Liao MJ, Eaton EN, Ayyanan A, Zhou AY, Brooks M, Reinhard F, Zhang CC, Shipitsin M, Campbell LL, Polyak K, Brisken C, Yang J and Weinberg RA: The epithelialmesenchymal transition generates cells with properties of stem cells. Cell 133: 704-715, 2008.

55 Thiery JP, Acloque H, Huang RY and Nieto MA: Epithelialmesenchymal transitions in development and disease. Cell 139: 871-890, 2009

56 Wolf I, Bose S, Williamson EA, Miller CW, Karlan BY and Koeffler HP: FOXA1: Growth inhibitor and a favorable prognostic factor in human breast cancer. Int J Cancer 120: 10131022, 2007

57 Kim YJ, Greer CB, Cecchini KR, Harris LN, Tuck DP and Kim TH: HDAC inhibitors induce transcriptional repression of high copy number genes in breast cancer through elongation blockade. Oncogene 32: 2828-2835, 2013.

58 Yan W, Liu S, Xu E, Zhang J, Zhang Y, Chen X and Chen X: Histone deacetylase inhibitors suppress mutant $p 53$ transcription via histone deacetylase 8. Oncogene 32: 599-609, 2013.

59 Somoza JR, Skene RJ, Katz BA, Mol C, Ho JD, Jennings AJ, Luong C, Arvai A, Buggy JJ, Chi E, Tang J, Sang BC, Verner E, Wynands R, Leahy EM, Dougan DR, Snell G, Navre M, Knuth MW, Swanson RV, McRee DE and Tari LW: Structural snapshots of human HDAC8 provide insights into the class I histone deacetylases. Structure 12: 1325-1334, 2004.

$60 \mathrm{Hu}$ E, Chen Z, Fredrickson T, Zhu Y, Kirkpatrick R, Zhang GF, Johanson K, Sung CM, Liu R and Winkler J: Cloning and characterization of a novel human class I histone deacetylase that functions as a transcription repressor. J Biol Chem 275: 15254-15264, 2000.

61 Oehme I, Deubzer HE, Wegener D, Pickert D, Linke JP, Hero B, Kopp-Schneider A, Westermann F, Ulrich SM, von Deimling $\mathrm{A}$, Fischer $\mathrm{M}$ and Witt $\mathrm{O}$ : Histone deacetylase 8 in neuroblastoma tumorigenesis. Clin Cancer Res 15: 91-99, 2009.
62 Yoshida M, Horinouchi S and Beppu T: Trichostatin A and trapoxin: novel chemical probes for the role of histone acetylation in chromatin structure and function. Bioessays 17: 423-430, 1995.

63 Vigushin DM, Ali S, Pace PE, Mirsaidi N, Ito K, Adcock I and Coombes RC: Trichostatin A is a histone deacetylase inhibitor with potent antitumor activity against breast cancer in vivo. Clin Cancer Res 7: 971-976, 2001.

64 Yang X, Ferguson AT, Nass SJ, Phillips DL, Butash KA, Wang SM, Herman JG and Davidson NE: Transcriptional activation of estrogen receptor alpha in human breast cancer cells by histone deacetylase inhibition. Cancer Res 60: 6890-6894, 2000.

65 Alao JP, Lam EW, Ali S, Buluwela L, Bordogna W, Lockey P, Varshochi R, Stavropoulou AV, Coombes RC and Vigushin DM: Histone deacetylase inhibitor trichostatin A represses estrogen receptor alpha-dependent transcription and promotes proteasomal degradation of cyclin D1 in human breast carcinoma cell lines. Clin Cancer Res 10: 8094-8104, 2004.

66 Ning L, Jaskula-Sztul R, Kunnimalaiyaan M and Chen H: Suberoyl bishydroxamic acid activates NOTCH1 signaling and suppresses tumor progression in an animal model of medullary thyroid carcinoma. Ann Surg Oncol 15: 2600-2605, 2008.

67 You BR and Park WH: Suberoyl bishydroxamic acid inhibits the growth of A549 lung cancer cells via caspase-dependent apoptosis. Mol Cell Biochem 344: 203-210, 2010.

68 Zhuang ZG, Fei F, Chen Y and Jin W: Suberoyl bis-hydroxamic acid induces p53-dependent apoptosis of MCF-7 breast cancer cells. Acta Pharmacol Sin 29: 1459-1466, 2008.

69 Yang $X$, Zhang N, Shi Z, Yang Z and Hu X: Histone deacetylase inhibitor suberoyl bis-hydroxamic acid suppresses cell proliferation and induces apoptosis in breast cancer cells. Mol Med Rep 11: 2908-2912, 2015.

70 Yoon MK, Mitrea DM, Ou L and Kriwacki RW: Cell cycle regulation by the intrinsically disordered proteins $\mathrm{p} 21$ and $\mathrm{p} 27$. Biochem Soc Trans 40: 981-988, 2012.

71 Jiang D, Wang X, Liu X and Li F: Gene delivery of cyclindependent kinase inhibitors p21 WAF1 and p27KIP1 suppresses proliferation of MCF-7 breast cancer cells in vitro. Breast Cancer 21: 614-623, 2014.

72 Danial NN: BCL-2 family proteins: critical checkpoints of apoptotic cell death. Clinical Cancer Res 13: 7254-7263, 2007.

73 Cregan SP, MacLaurin JG, Craig CG, Robertson GS, Nicholson DW, Park DS, and Slack RS: BAX-dependent caspase-3 activation is a key determinant in p53-induced apoptosis in neurons. J Neurosci 19: 7860-7869, 1999.

74 Ganai SA: Panobinostat: The small molecule metalloenzyme inhibitor with marvelous anticancer activity. Curr Top Med Chem 16: 427-434, 2016.

75 Zhou Q, Atadja P and Davidson NE: Histone deacetylase inhibitor LBH589 reactivates silenced estrogen receptor alpha (ER) gene expression without loss of DNA hypermethylation. Cancer Biol Ther 6: 64-69, 2007.

76 Kubo M, Kanaya N, Petrossian K, Ye J, Warden C, Liu Z, Nishimura R, Osako T, Okido M, Shimada K, Takahashi M, Chu $\mathrm{P}$, Yuan YC and Chen S: Inhibition of the proliferation of acquired aromatase inhibitor-resistant breast cancer cells by histone deacetylase inhibitor LBH589 (panobinostat). Breast Cancer Res Treat 137: 93-107, 2013. 
77 Tate CR, Rhodes LV, Segar HC, Driver JL, Pounder FN, Burow ME and Collins-Burow BM: Targeting triple-negative breast cancer cells with the histone deacetylase inhibitor panobinostat. Breast Cancer Res 14: R79, 2012.

78 Tan WW, Allred JB, Moreno-Aspitia A, Northfelt DW, Ingle JN, Goetz MP and Perez EA: Phase I study of panobinostat (LBH589) and letrozole in postmenopausal metastatic breast cancer patients. Clin Breast Cancer 16: 82-86, 2016.

79 Scheel C and Weinberg RA: Cancer stem cells and epithelialmesenchymal transition: concepts and molecular links. Semin Cancer Biol 22: 396-403, 2012.

80 Singh A and Settleman J: EMT, cancer stem cells and drug resistance: an emerging axis of evil in the war on cancer. Oncogene 29: 4741-4751, 2010.

81 Van Horssen R, Hollestelle A, Rens JA, Eggermont AM, Schutte $M$ and Ten Hagen TL: E-Cadherin promotor methylation and mutation are inversely related to motility capacity of breast cancer cells. Breast Cancer Res Treat 136: 365-377, 2012.

82 Shah P, Gau Y and Sabnis G: Histone deacetylase inhibitor entinostat reverses epithelial to mesenchymal transition of breast cancer cells by reversing the repression of E-cadherin. Breast Cancer Res Treat 143: 99-111, 2014.

83 Naldini A, Filippi I, Cini E, Rodriquez M, Carraro F and Taddei M: Downregulation of hypoxia-related responses by novel antitumor histone deacetylase inhibitors in MDAMB231 breast cancer cells. Anticancer Agents Med Chem 12: 407-413, 2012.

84 Debeb BG, Lacerda L, Xu W, Larson R, Solley T, Atkinson R, Sulman EP, Ueno NT, Krishnamurthy S, Reuben JM, Buchholz TA and Woodward WA: Histone deacetylase inhibitors stimulate dedifferentiation of human breast cancer cells through WNT/ $\beta$ catenin signaling. Stem Cells 30: 2366-2377, 2012.

85 Giudice FS, Pinto DS Jr, Nor JE, Squarize CH and Castilho RM: Inhibition of histone deacetylase impacts cancer stem cells and induces epithelial-mesenchyme transition of head and neck cancer. PloS One 8: e58672, 2013.

86 Yardley DA, Ismail-Khan RR, Melichar B, Lichinitser M, Munster PN, Klein PM, Cruickshank S, Miller KD, Lee MJ and Trepel JB: Randomized phase II, double-blind, placebocontrolled study of exemestane with or without entinostat in postmenopausal women with locally recurrent or metastatic estrogen receptor-positive breast cancer progressing on treatment with a nonsteroidal aromatase inhibitor. J Clin Oncol 31: 2128-2135, 2013.

87 Sami S, Hoti N, Xu HM, Shen Z and Huang X: Valproic acid inhibits the growth of cervical cancer both in vitro and in vivo. J Biochem 144: 357-362, 2008.

88 Kurwale N, Garg K, Arora A, Chandra PS and Tripathi M: Valproic acid as an antiepileptic drug: Is there a clinical relevance for the epilepsy surgeon? Epilepsy Res 127: 191-194, 2016.

89 Peselow ED, Clevenger S and IsHak WW: Prophylactic efficacy of lithium, valproic acid, and carbamazepine in the maintenance phase of bipolar disorder: a naturalistic study. Int Clin Psychopharmacol 31: 218-223, 2016.

90 Gottlicher M, Minucci S, Zhu P, Kramer OH, Schimpf A, Giavara S, Sleeman JP, Lo Coco F, Nervi C, Pelicci PG and Heinzel T: Valproic acid defines a novel class of HDAC inhibitors inducing differentiation of transformed cells. EMBO J 20: 6969-6978, 2001.
91 Hrzenjak A, Moinfar F, Kremser ML, Strohmeier B, Staber PB, Zatloukal $\mathrm{K}$ and Denk $\mathrm{H}$ : Valproate inhibition of histone deacetylase 2 affects differentiation and decreases proliferation of endometrial stromal sarcoma cells. Mol Cancer Ther 5: 22032210, 2006.

92 Fortunati N, Bertino S, Costantino L, Bosco O, Vercellinatto I, Catalano MG and Boccuzzi G: Valproic acid is a selective antiproliferative agent in estrogen-sensitive breast cancer cells. Cancer Lett 259: 156-164, 2008.

93 Travaglini L, Vian L, Billi M, Grignani $F$ and Nervi C: Epigenetic reprogramming of breast cancer cells by valproic acid occurs regardless of estrogen receptor status. Int J Biochem Cell Biol 41: 225-234, 2009.

94 Zhang L, Wang G, Wang L, Song C, Leng Y, Wang X and Kang $\mathrm{J}$ : VPA inhibits breast cancer cell migration by specifically targeting HDAC2 and down-regulating Survivin. Mol Cell Biochem 361: 39-45, 2012.

95 Mawatari T, Ninomiya I, Inokuchi M, Harada S, Hayashi H, Oyama K, Makino I, Nakagawara H, Miyashita T, Tajima H, Takamura H, Fushida $\mathrm{S}$ and Ohta T: Valproic acid inhibits proliferation of HER2-expressing breast cancer cells by inducing cell cycle arrest and apoptosis through HSP70 acetylation. Int J Oncol 47: 2073-2081, 2015.

96 Pratt WB and Toft DO: Regulation of signaling protein function and trafficking by the hsp90/hsp70-based chaperone machinery. Exp Biol Med 228: 111-133, 2003.

97 Terranova-Barberio M, Roca MS, Zotti AI, Leone A, Bruzzese F, Vitagliano C, Scogliamiglio G, Russo D, D'Angelo G, Franco R, Budillon A, Di Gennaro E: Valproic acid potentiates the anticancer activity of capecitabine in vitro and in vivo in breast cancer models via induction of thymidine phosphorylase expression. Oncotarget 7: 7715-7731, 2016.

98 Xiong F, Mou YZ and Xiang XY: Inhibition of mouse B16 melanoma by sodium butyrate correlated to tumor associated macrophages differentiation suppression. Int J Clin Exp Med 8: 4170-4174, 2015.

99 Demary K, Wong L and Spanjaard RA: Effects of retinoic acid and sodium butyrate on gene expression, histone acetylation and inhibition of proliferation of melanoma cells. Cancer Lett 163: 103-107, 2001

100 Jazirehi AR: Regulation of apoptosis-associated genes by histone deacetylase inhibitors: implications in cancer therapy. Anticancer Drugs 21: 805-813, 2010.

$101 \mathrm{Li} \mathrm{L}$, Sun Y, Liu J, Wu X, Chen L, Ma L and Wu P: Histone deacetylase inhibitor sodium butyrate suppresses DNA double strand break repair induced by etoposide more effectively in MCF-7 cells than in HEK293 cells. BMC Biochem 16: 2, 2015.

102 Greenberg VL, Williams JM, Boghaert E, Mendenhall M, Ain $\mathrm{KB}$ and Zimmer SG: Butyrate alters the expression and activity of cell cycle components in anaplastic thyroid carcinoma cells. Thyroid 11: 21-9, 2001

103 Chopin V, Toillon RA, Jouy N and Le Bourhis X: Sodium butyrate induces P53-independent, Fas-mediated apoptosis in MCF-7 human breast cancer cells. Br J Pharmacol 135: 79-86, 2002.

104 Tor YS, Yazan LS, Foo JB, Armania N, Cheah YK, Abdullah R, Imam MU, Ismail $\mathrm{N}$ and Ismail $\mathrm{M}$ : Induction of apoptosis through oxidative stress-related pathways in MCF-7, human breast cancer cells, by ethyl acetate extract of Dillenia suffruticosa. BMC Complement Altern Med 14: 55, 2014. 
105 Wang Y, Hu PC, Ma YB, Fan R, Gao FF, Zhang JW and Wei L: Sodium butyrate-induced apoptosis and ultrastructural changes in MCF-7 breast cancer cells. Ultrastruct Pathol 40: 200-204, 2016.

106 Saito A, Yamashita T, Mariko Y, Nosaka Y, Tsuchiya K, Ando T, Suzuki T, Tsuruo T and Nakanishi O: A synthetic inhibitor of histone deacetylase, MS-27-275, with marked in vivo antitumor activity against human tumors. Proc Natl Acad Sci USA 96: 4592-4597, 1999.

107 Lee KW, Kim JH, Park JH, Kim HP, Song SH, Kim SG, Kim TY, Jong HS, Jung KH, Im SA, Kim TY, Kim NK and Bang YJ: Antitumor activity of SK-7041, a novel histone deacetylase inhibitor, in human lung and breast cancer cells. Anticancer Res 26: 3429-3438, 2006.

108 Park JH, Jung Y, Kim TY, Kim SG, Jong HS, Lee JW, Kim NK, Kim TY and Bang YJ: Class I histone deacetylase-selective novel synthetic inhibitors potently inhibit human tumor proliferation. Clin Cancer Res 2004 10: 5271-5281, 2004.

109 Ryu JK, Lee WJ, Lee KH, Hwang JH, Kim YT, Yoon YB and Kim CY: SK-7041, a new histone deacetylase inhibitor, induces G2-M cell-cycle arrest and apoptosis in pancreatic cancer cell lines. Cancer Lett 237: 143-154, 2006.

110 Hait NC, Avni D, Yamada A, Nagahashi M, Aoyagi T, Aoki H, Dumur CI, Zelenko Z, Gallagher EJ, Leroith D, Milstien S, Takabe K and Spiegel S: The phosphorylated prodrug FTY720 is a histone deacetylase inhibitor that reactivates ER $\alpha$ expression and enhances hormonal therapy for breast cancer. Oncogenesis 4: e156, 2015.

111 Prestegui-Martel B, Bermudez-Lugo JA, Chavez-Blanco A, Duenas-Gonzalez A, Garcia-Sanchez JR, Perez-Gonzalez OA, Padilla-Martínez II, Fragoso-Vázquez MJ, Mendieta-Wejebe JE, Correa-Basurto AM, Méndez-Luna D, Trujillo-Ferrara J and Correa-Basurto J: $N$-(2-Hydroxyphenyl)-2-propylpentanamide, a valproic acid aryl derivative designed in silico with improved anti-proliferative activity in HeLa, rhabdomyosarcoma and breast cancer cells. J Enzyme Inhib Med Chem 2: 1-10, 2016.

112 Marks P, Rifkind RA, Richon VM, Breslow R, Miller T and Kelly WK: Histone deacetylases and cancer: causes and therapies. Nat Rev Cancer 1: 194-202, 2001.

113 Keen JC, Yan L, Mack KM, Pettit C, Smith D, Sharma D and Davidson NE: A novel histone deacetylase inhibitor, Scriptaid, enhances expression of functional estrogen receptor alpha (ER) in ER-negative human breast cancer cells in combination with 5aza-2'-deoxycytidine. Breast Cancer Res Treat 81: 177-186, 2003.

114 Huang WJ, Chen CC, Chao SW, Yu CC, Yang CY, Guh JH, Lin YC, Kuo CI, Yang P and Chang CI: Synthesis and evaluation of aliphatic-chain hydroxamates capped with osthole derivatives as histone deacetylase inhibitors. Eur J Med Chem 46: 4042-4049, 2011.

115 Huang WJ, Tang YA, Chen MY, Wang YJ, Hu FH, Wang TW, Chao SW, Chiu HW, Yeh YL, Chang HY, Juan HF, Lin P and Wang YC: A histone deacetylase inhibitor YCW1 with antitumor and anti-metastasis properties enhances cisplatin activity against non-small cell lung cancer in preclinical studies. Cancer Lett 346 : 84-93, 2014.
116 Wang TT and Phang JM: Effects of estrogen on apoptotic pathways in human breast cancer cell line MCF-7. Cancer Res 55: 2487-2489, 1995.

117 Hanna RA, Quinsay MN, Orogo AM, Giang K, Rikka S and Gustafsson AB: Microtubule-associated protein 1 light chain 3 (LC3) interacts with BNIP3 protein to selectively remove endoplasmic reticulum and mitochondria via autophagy. J Biol Chem 287: 19094-19104, 2012.

118 Zhang J and Ney PA: Role of BNIP3 and NIX in cell death, autophagy, and mitophagy. Cell Death Differ 16: 939-946, 2009.

119 Burton TR, Eisenstat DD and Gibson SB: BNIP3 (BCL-2 19 kDa interacting protein) acts as transcriptional repressor of apoptosisinducing factor expression preventing cell death in human malignant gliomas. J Neurosci 29: 4189-4199, 2009.

120 Sowter HM, Ferguson M, Pym C, Watson P, Fox SB, Han C and Harris AL: Expression of the cell death genes BNIP3 and NIX in ductal carcinoma in situ of the breast; correlation of BNIP3 levels with necrosis and grade. J Pathol 201: 573-580, 2003.

121 Gromek SM, deMayo JA, Maxwell AT, West AM, Pavlik CM, Zhao Z, Li J, Wiemer AJ, Zweifach A and Balunas MJ: Synthesis and biological evaluation of santacruzamate A analogues for antiproliferative and immunomodulatory activity. Bioorg Med Chem 24: 5183-5196, 2016.

122 Li C, Tang C, Hu Z, Zhao C, Li C, Zhang S, Dong C, Zhou HB, Huang J: Synthesis and structure-activity relationships of novel hybrid ferrocenyl compounds based on a bicyclic core skeleton for breast cancer therapy. Bioorg Med Chem 24: 3062-3074, 2016.

123 Rodriguez-Paredes M and Esteller M: Cancer epigenetics reaches mainstream oncology. Nat Med 17: 330-339, 2011.

124 Slingerland M, Guchelaar HJ and Gelderblom H: Histone deacetylase inhibitors: an overview of the clinical studies in solid tumors. Anticancer Drugs 25: 140-149, 2014.

125 Fan J, Yin WJ, Lu JS, Wang L, Wu J, Wu FY, Di GH, Shen ZZ and Shao ZM: ER alpha negative breast cancer cells restore response to endocrine therapy by combination treatment with both HDAC inhibitor and DNMT inhibitor. J Cancer Res Clin Oncol 134: 883-890, 2008.

126 Jang ER, Lim SJ, Lee ES, Jeong G, Kim TY, Bang YJ and Lee JS: The histone deacetylase inhibitor trichostatin A sensitizes estrogen receptor alpha-negative breast cancer cells to tamoxifen. Oncogene 23: 1724-1736, 2004.

127 Thomas S, Thurn KT, Bicaku E, Marchion DC and Munster PN: Addition of a histone deacetylase inhibitor redirects tamoxifentreated breast cancer cells into apoptosis, which is opposed by the induction of autophagy. Breast Cancer Res Treat 130: 437447, 2011 